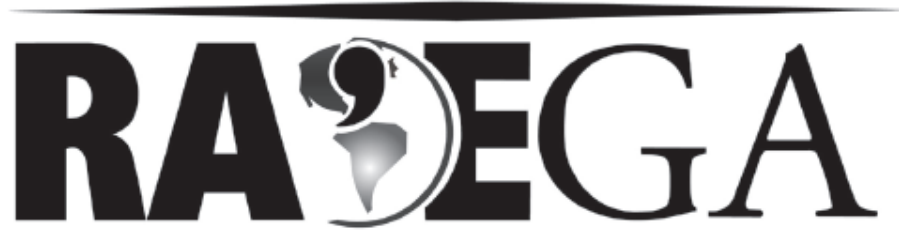

O ESPAÇO GEOGRÁFICO EM ANÁLISE

\title{
LINGUAGEM E CULTURA NO ESPAÇO DOS PRÁTICOS DO RIO MADEIRA (RONDÔNIA): UMA LEITURA DAS REPRESENTAÇÕES ${ }^{1}$
}

\section{LANGAGE AND CULTURE IN THE SPACE OF MADEIRA RIVER PRACTICALS (RONDÔNIA): A READING OF REPRESENTATIONS}

\author{
Lucileyde Feitosa Sousa ${ }^{2}$
}

\section{RESUMO}

O espaço do rio Madeira, no Estado de Rondônia, é repleto de representações, signos e linguagens que fazem parte do mundo vivido dos práticos do rio Madeira. Analisou-se os espaços de representação desses práticos, procurando fazer essa interface da Geografia Cultural com os estudos baktinianos de modo a verificar como os práticos elaboram o conjunto de explicações de seu espaço, tido como construtor de signos e de sentidos, ambos construídos socialmente nessa interação entre os sujeitos, mediante as relações afetivas, sociais e culturais. Os estudos de representação, sob o viés humanista cultural, tornam-se um caminho de entendimento desse espaço habitado por homens que constroem uma geografia cultural da Amazônia.

Palavras-chave: Amazônia; Práticos; Rio Madeira; Representação. Linguagem.

\footnotetext{
${ }^{1}$ Este trabalho faz parte da Construção de uma Tese de doutoramento e vem sendo desenvolvido, sob a orientação da Profa. Dra. Salete Kozel, do Programa de Pós-graduação em Geografia, da Universidade Federal do Paraná (UFPR) e sob a co-orientação da Profa. Dra. Maria das Graças Silva Nascimento Silva, da Universidade Federal de Rondônia (UNIR).

2 Doutoranda do Programa de Pós-graduação em Geografia - UFPR, Bolsista CAPES/PDEE, com estágio na Universidade do Minho, sob a co-orientação estrangeira do Prof. Dr. João Sarmento. E-mail: lucileyde@feitosa.org
} 


\title{
ABSTRACT
}

The area of the Madeira River in Rondônia State, is full of ideas, symbols and languages that are part of the lived world of practical Madeira River. We analyzed the representation of these practical spaces, trying to make that interface the Cultural Geography with baktinianos studies to ascertain how elaborate the set of practical explanations of their space, taken as a builder of signs and meanings, both socially constructed in that interaction among individuals through the personal relationships, social and cultural rights. Studies of representation, under the humanist cultural bias, they become a way of understanding this space inhabited by men who build a cultural geography of the Amazon.

Keywords: Amazon; Práticos; Madeira River; Representation; Language.

\begin{abstract}
"A palavra é uma espécie de ponte lançada entre mim e os outros. Se ela se apóia sobre mim numa extremidade, na outra apóia-se sobre o meu interlocutor. A palavra é o território comum do locutor e interlocutor".
\end{abstract}

Mikhail Bakhtin

Este artigo se constitui a partir de um processo dialógico, da leitura da palavra como território comum do locutor e do interlocutor, delineado pelo convívio e troca de experiências com os práticos ${ }^{3}$ do rio Madeira, no Estado de Rondônia. Pretendeu-se analisar as representações construídas por esses profissionais da navegação (práticos) sobre o seu espaço vivido, tendo como referência o papel da linguagem nessa interface com a Geografia Cultural.

$\mathrm{Na}$ análise que segue, os profissionais da navegação do rio Madeira elaboram o conjunto de explicações de seu espaço, tido como construtor de signos, os quais são construídos socialmente, nessa interação do homem com o seu meio e no encontro com o outro, no expressar da palavra ao outro que se faz sujeito de todo um discurso impregnado de cultura e de história, considerando toda uma poética construída através das relações afetivas, simbólicas e culturais.

\footnotetext{
${ }^{3}$ É o sujeito nascido ou não na área ribeirinha da Amazônia. Conhece, orienta, navega e pilota os barcos nas épocas das cheias e vazantes, Sousa, 2004.
} 
Priorizou-se nesse percurso investigativo uma vertente geográfica de cunho humanista cultural, sobretudo, uma leitura de entendimento das representações no âmbito amazônico, fazendo esta interface com os estudos bakhtinianos, no desvendar do mundo vivido dos práticos do rio Madeira.

O texto encontra-se estruturado em cinco momentos: a) $\mathbf{O}$ território da palavra silenciada ou dialógica? $O$ espaço do rio Madeira, com ênfase a área de pesquisa e aos processos interlocutivos; b) Os práticos: sujeitos que resistem à invisibilidade social, destacam-se os sujeitos da pesquisa e o trabalho desenvolvido por eles a bordo das embarcações; c) Do Madeira ao campo das representações: dialogo possível com os homens da Amazônia, destaca-se o diálogo com a teoria aqui escolhida; d) 0 espaço do barco: da representação indo ao encontro da linguagem; buscou-se estabelecer o encontro de diálogos com a teoria e, por fim, a ênfase a Representação do Espaço dos práticos como sendo mediada pela Linguagem.

\section{O território da palavra silenciada ou dialógica? O espaço do rio Madeira}

Atualmente em Rondônia há uma previsão do aumento da oferta da produção de energia, capaz de impulsionar o tão esperado desenvolvimento nacional, ainda mais em regiões geograficamente desassistidas, como é o caso da Amazônia. Encontra-se em fase de construção na cidade de Porto Velho duas usinas hidrelétricas de grande porte no rio Madeira, denominadas de Santo Antonio e Jirau, as quais já começam a trazer conseqüências e impactos ambientais em todos os níveis, além da promoção de uma nova dinâmica de reorganização do espaço e mudança da qualidade de vida da população local.

A construção das duas hidrelétricas, por exemplo, atingirão fortemente a população residente em seu raio de abrangência, com alagação das terras e desapropriação de famílias ribeirinhas e indígenas, as quais, além de morarem há mais de cinqüenta anos nessa região, possuem como únicos meios de 
subsistência a pesca, a agricultura de subsistência, extrativismo e a construção de embarcações.

Além disso, a navegação já começa a ficar prejudicada devido ao represamento parcial da água, já sendo percebido por ribeirinhos e barqueiros, tendo em vista o aparecimento dos inúmeros bancos de areia e praias que se formam ao longo do rio Madeira, sendo tais obstáculos reforçados com a ação intensa de garimpagem de ouro nessa área de pesquisa.

É nesse cenário de dificuldades, de contradições, principalmente de pouca assistência do Poder Público no tocante ao Segmento de Transporte de Passageiros e Cargas que destacamos uma categoria pouco estudada e silenciada na Amazônia: os Práticos.

Os práticos trabalham e moram no espaço ribeirinho, o qual se torna marcante, segundo Silva e Souza Filho (2002), por conter uma organização social diferenciada da urbana, haja vista a presença de uma cosmovisão marcada pela presença das águas, tendo sua economia baseada na pesca, pequena produção agrícola (mandioca, para a produção de farinha), pratica a coleta de produtos da mata (castanha, açaí, pupunha, abacaba, patoá, etc). Outro aspecto de destaque nesse espaço é a construção de embarcações de madeiras, podendo variar desde canoas, rabetas e barcos recreios ${ }^{4}$.

Neste espaço ribeirinho, há um destaque para a linguagem que permeia toda a construção desse espaço, através das relações afetivas, sociais e culturais que mantém com os ribeirinhos. Como diz Claval (2009) a dimensão cultural desse povo merece ser estudada pelos geógrafos, não apenas sob o viés ecológico, mas como unidade cultural, sendo que a coerência e a identidade dos ribeirinhos podem ser preservados. Portanto, é o desafio da geografia cultural da Amazônia.

Em relação ao nosso recorte espacial ficou sendo o rio Madeira, principal rio do Estado de Rondônia e o mais importante afluente da margem direita do rio Amazonas, o qual passa por um processo de reconfiguração espacial, por ocasião da construção das usinas hidrelétricas (Jirau e Santo Antonio):

\footnotetext{
${ }^{4}$ Embarcações motorizadas que transportam cargas e passageiros, costumam fazer linhas regulares paras as mais diversas localidades ribeirinhas de acordo com SOUSA (2004).
} 


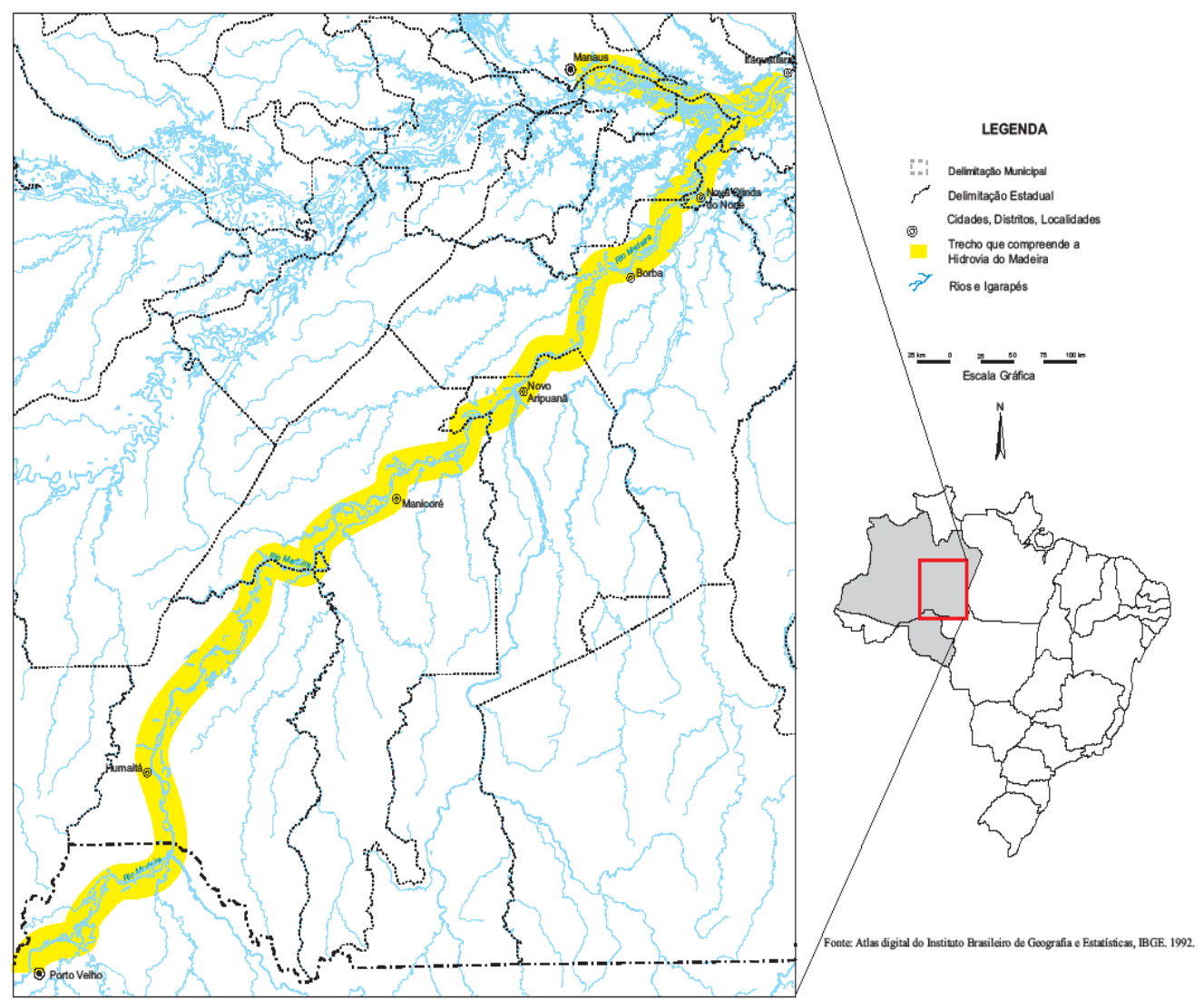

Nesta área, nos interessa investigar as representações que os práticos constroem sobre o seu espaço vivido. Temos trabalhado, ao longo de 12 anos, com essa categoria na Amazônia: os práticos. Esses atores são importantes no transporte fluvial, pois possuem a experiência, o conhecimento do espaço ribeirinho, o saber espacial, sendo essencial no trabalho realizado a bordo das embarcações motorizadas, colaborando com a preservação da vida dos passageiros e, sobretudo, na prevenção de acidentes, especialmente dos naufrágios.

A construção desse percurso investigativo perpassou por um trabalho de interlocução com os práticos, através da realização de trabalhos de campo, de entrevistas, observação participante, realização de viagens com o grupo, levantamento bibliográfico, e principalmente a participação nos grupos de pesquisa $^{5}$, nos levando ao entendimento de como essa categoria de profissionais representa esse espaço do rio Madeira.

\footnotetext{
${ }^{5}$ Estudos Modos de Vida e Culturas Amazônica/GEPCULTURA, da Universidade Federal de Rondônia e Grupo de pesquisa: Território, Cultura e Representação, da Universidade Federal do Paraná.
} 
Fazer pesquisa com os práticos tornou-se um desafio acadêmico e pessoal, mesclado por uma soma de opções: escolha, curiosidade, compromisso acadêmico, tendo em vista dar visibilidade ao grupo excluído das políticas públicas de transporte na região amazônica.

Das vivências e experiências com os práticos chegamos aos estudos de representação, na tentativa de compreender as práticas espaciais e culturais desse grupo no rio Madeira, considerando que a representação segundo Kozel (2009) é uma forma de linguagem impregnada de significados e valores sociais refletindo a realidade ou vivência social dos sujeitos.

O rio Madeira se relaciona com uma poética, cujo expoente maior é a liberdade do navegar pelos diversos rios e canais, furos, remansos, construindo um conjunto de representações que muito revela esse viver amazônico em áreas ribeirinhas e, muitas vezes, isoladas da Amazônia.

Assim, em termos de representação, a linguagem caracteriza e marca o homem enquanto sujeito cultural e social; conhecer o mundo vivido dos profissionais da navegação nos permitirá compreender as experiências desses homens que praticam uma navegação tão singular na Amazônia, os quais desde muito cedo ajudam suas famílias nas atividades de pesca, agricultura, garimpagem de ouro, construção de embarcações e trabalho na roça.

O homem da Amazônia constrói olhares e saberes espaciais como nos afirma Callai (2003, p. 64):

\footnotetext{
A geografia ao falar das coisas do mundo da vida, fala dos espaços construídos pelos homens, que em sua trajetória marcaram os lugares com os resultados de luta pela sobrevivência. A tarefa da Geografia na análise da sociedade é exatamente debruçar-se sobre a realidade com o olhar espacial.
}

Entende-se que a ciência geográfica há muito de colaborar para o entendimento desse modo de vida que é construído num espaço como o rio Madeira e que marca a organização do grupo e possibilidade de dar voz a esses habitantes, tirando-lhes desse processo de silenciamento em relação às políticas públicas empreendidas na região e que, muitas vezes, apenas alimenta o silenciamento dessa cultura amazônica de grande diversidade. 


\section{Os práticos: sujeitos que resistem à invisibilidade social}

O termo prático segundo Sousa (2004) adquire dois enfoques: o primeiro evidencia o profissional habilitado pela Marinha Mercante e que atua em grandes navios, cabendo-lhe a função de atracar o navio, sendo necessário o conhecimento do porto. De outro lado, existem os práticos que conhecem e estudam os rios, viajam nas embarcações, orientam e pilotam os barcos nos mais diversos rios. Eles não são reconhecidos oficialmente pela Capitania dos Portos nesta categoria, mas as empresas de navegação recorrem ao trabalho desses sujeitos nos mais diversos rios e a forma de contratação deles se dá através de informações de terceiros.

Essa categoria de práticos ribeirinhos é pouco estudada na Amazônia, apesar de serem atores importantes no transporte fluvial como já mencionado na parte introdutória desse artigo. O prático com o qual trabalhamos significa no rio Madeira o sujeito que conhece, orienta, navega e pilota os barcos com segurança nas épocas das cheias e vazantes, sendo considerada a importância do seu trabalho na navegação, principalmente na vazante onde os acidentes são freqüentes em virtude do aparecimento dos bancos de areia, praias, pedrais e a habilidade do prático é indispensável no Madeira.

Os Práticos são jovens e adultos, às vezes não alfabetizados, ora possuidores do ensino fundamental incompleto. Nesse contexto, Sousa (2004) identificou dois perfis de práticos:

1 Nascido e criado em áreas ribeirinhas: na faixa etária de sete a dez anos, as crianças começam a acompanhar seus pais, parentes ou amigos nas pescarias, é o momento de ultrapassar a fase deliciosa das brincadeiras com miniaturas de embarcações e começar a ajudar nos pequenos afazeres como olhar e tirar água que se acumula no fundo da canoa, ajudar a desenrolar a malhadeira ou ir simplesmente acompanhar o pai, ocorrendo o início do aprendizado sobre o espaço vivido.

O aprendizado se realiza pela prática, pela convivência grupal; é o saber remar uma canoa, identificar um repiquete, um rebojo diferente, conhecer e marcar o canal, conhecer as passagens perigosas e, esse registro é mental, 
sendo transmitido oralmente de pai para filho, através de todo um processo de interlocução.

2ํo Prático não nascido em área ribeirinha: esse prático precisa estudar e conhecer o rio Madeira para fins de obtenção de emprego, significando um trunfo profissional. Muitas das empresas visitadas ao longo de nossas pesquisas evidenciaram que dependem da experiência do Prático para transportar com segurança suas mercadorias. Os práticos experientes são os responsáveis pela transmissão do conhecimento aos mais jovens, é preciso ter um senso de observação aguçado, em se tratando de identificar banco de areia, pedral e toco. Existem signos, a exemplo de um banzeiro diferente, que denunciam a presença de obstáculos no rio; identificá-los é uma das estratégias de segurança.

O prático precisa viajar de dia e de noite para conhecer minuciosamente o rio, o fato de viajar somente durante o dia não significa que realmente conheça o rio. Se por ventura for solicitado que este prático, acostumado a viajar durante o dia, viaje à noite ficará perdido, pois não gravou as árvores e nem o canal. Só conhece o canal durante o dia.

Existe uma distinção no trabalho do prático em relação ao turno de trabalho. Ainda precisa viajar constantemente no rio, caso fique sessenta dias sem viajar e, ao retornar ao trabalho, ficará desorientado, terá que voltar a estudar o rio novamente, pois o canal muda sempre.

De modo geral, cabem aos práticos duas funções tais como: a de orientar o comandante como toda a tripulação quanto a melhor forma de navegar em trechos difíceis; segundo conduzir a embarcação com segurança e responsabilidade. Muitos dos ribeirinhos falam que o futuro prático já nasce dentro da canoa devido à facilidade que detém ao manejá-la.

A navegação praticada pelos práticos na Amazônia é marcada pelo conjunto de representações existentes no universo das águas e das matas. $O$ grupo de práticos apresenta desenvoltura na arte do aconselhamento e orientação a bordo das embarcações recreios, as quais transportam passageiros e cargas no rio Madeira. Essas viagens costumam durar em torno de três a quinze dias, dependendo da carga que chega ao barco, pois as 
mercadorias vem de fora da cidade de onde sai o barco, do percurso a ser navegado, da época (cheias ou vazantes) a ser escolhida, da potência do motor da embarcação e espera-se que não haja imprevistos como problemas mecânicos que a embarcação possa a vir a apresentar.

Cabe destacar, que as viagens realizadas nesses rios da região levam os passageiros a enxergarem esse modo de vida amazônico, com as suas dificuldades, esperanças, anseios, além dos mitos, das ilhas encantadas, dos lugares santos e protegidos por entidades sobrenaturais. Sem dúvida, ao primeiro olhar, o passageiro se depara com um universo indescritível de belezas naturais, de imensidão de águas, variedade de pássaros e de animais silvestres, fazendo parte dessa vivência cotidiana com o meio ambiente os elementos das paisagens do medo e do prazer.

Ao mesmo tempo, a noção de medo, de estranhamento encontra-se de forma sutil ou mesmo avassaladora nesse encontro do homem turista ou mesmo do nativo com a natureza, haja vista a possibilidade de desfrutar de uma atividade turística de modo intenso, respeitando a natureza na qual se apresenta muitas vezes ameaçadora na Amazônia.

Os práticos acabam exercendo essa função de cronistas do viver ribeirinho, pois eles divulgam, falam do ambiente ribeirinho, evidenciando todas as peculiaridades e obstáculos possíveis, além de manterem uma relação que ultrapassa a esfera econômica no que diz respeito a levar e trazer passageiros, além de mercadorias dos ribeirinhos. Construíram a partir de uma relação dialética com a natureza e com os ribeirinhos, uma expressão singular e de grande riqueza das representações simbólicas, constituindo-se um produtor de espaço, de símbolos, de signos e de enunciações diversas.

\section{Do Madeira ao campo das representações: dialogo possível com os homens da Amazônia}

De início, o nosso fundamento se baseia na importância das representações na Amazônia, considerando a relação do homem com o seu mundo vivido, com a descrição de elementos que são percebidos e 
interpretados pelos diversos sujeitos que os experienciam o seu espaço. Os signos sociais evidenciam a riqueza das experiências encontradas nessa relação intersubjetiva com o lugar, com o espaço que o homem habita. Nesse sentido, Kozel (2007, p. 120) chama atenção que:

(...) essa apreensão do espaço relaciona-se às diferentes perspectivas que se fazem presentes na visão de mundo de cada ser humano. As experiências que os seres humanos tem dos elementos do espaço se constituem diferencial no momento de sua representação. E representação se faz através dos signos.

Esses signos podem ser construídos por intermédio das paisagens, das imagens, formas, odores, sabores, sendo fenômenos do mundo exterior, portanto, são produtos sociais. E sobre este aspecto, podemos evidenciar que o cotidiano dos práticos e ribeirinhos é ligado ao universo das águas e o valor das imagens evocadas a partir do elemento água congrega uma vasta representação como a dos "seres encantados", sendo apresentado uma dimensão do imaginário no espaço.

Todavia, o campo das representações e sob a égide da geografia humanista cultural poderá oportunizar a compreensão dos espaços vividos dos homens amazônicos, levando-se em conta as imagens produzidas a partir das relações afetivas e culturais com as quais mantém com o lugar. Portanto, esta abordagem humanista cultural torna-se pertinente, à medida que prioriza 0 estudo do indivíduo frente ao mundo, pois focaliza o lugar, o espaço como gesto vivido pelas experiências humanas, respeitando a individualidade de cada ser humano.

Desta maneira, trouxemos a contribuição de autores da geografia cultural, priorizando as representações, atendo-se a uma leitura bakhtiniana no entendimento da construção do espaço de representação dos práticos.

O espaço é entendido como entidade verbalizada pela linguagem, cujos signos são construídos socialmente. De acordo com Kozel (2007, p. 117) o "espaço não é somente apreendido através dos sentidos, ele referenda uma relação estabelecida pelo ser humano, emocionalmente de acordo com as suas experiências espaciais". 
Esse espaço é constituído de linguagem impregnada de significados e valores sociais, os quais refletem uma vivência social, significados e experiências espaciais mediada pela linguagem no espaço de representação do rio Madeira.

A contribuição de Bakhtin (1999), na interface com os estudos de representação, traz uma concepção de linguagem dialógica que leva em conta o diálogo, muitas vezes conflituoso ou não, da interação verbal entre os interlocutores e da construção do signo vivo e dinâmico. Em outras palavras, o signo emerge desse processo de interação verbal que ocorre entre os sujeitos de forma organizada e colabora para o entendimento do espaço de representação.

Em Bakhtin (1999) a linguagem ocupa um lugar de destaque nas suas análises, priorizando o estudo do dialogismo, dos enunciados. Destaca para tanto uma linguagem viva, plúri, múltipla, que resulta da criação humana acontecida na história através das relações sociais: "O sujeito como tal não pode ser percebido nem estudado como coisa, posto que sendo sujeito não pode, se quiser continuar sê-lo permanecer sem voz, portanto, seu conhecimento, só pode ter um caráter dialógico". (1999, p.117)

O dialogismo é o princípio constitutivo da linguagem, pressupõe o espaço de interação entre o eu e o tu ou entre o eu e o outro, trazendo de forma significativa a perspectiva de outra voz, do outro. Esse entrecruzamento de várias vozes evidencia as linguagens diversificadas, os signos construídos historicamente e os processos de significação do grupo.

Os homens no espaço do rio Madeira atuam como elementos articuladores da própria linguagem. Há várias vozes nesse processo enunciativo da palavra, gerando significados, vozes que ecoam no momento da fala ao longo das viagens nos barcos. Isto é, o dialogismo traz de forma significativa a perspectiva de outra voz, torna-se o espaço de interação, da interlocução.

As contribuições de Bakhtin colaboram com a construção de um olhar voltado para o sujeito prático, considerando que a linguagem atravessa o indivíduo provocando uma interação dinâmica e reveladora de significados 
espaciais. Esta concepção dialógica de linguagem bakhtiniana leva em conta o homem como sujeito histórico e social, que não se deixa silenciar, mas que apresenta a capacidade de dialogar com os outros, de trazer sempre a perspectiva de outra voz e de incorporá-la no seu discurso.

O dialogismo para Bakhtin é um princípio constitutivo da linguagem, assim, cada mapa mental é considerado um produto de muitas vozes ou de muitos outros discursos. Por sua vez, a linguagem cria seus signos absorvidos, vivenciados e utilizados pelo meio social, desencadeando sensações, emoções e refletindo uma determinada realidade.

Bakhtin, mostra que é impossível pensar o homem fora das relações que o ligam ao outro e que o discurso se elabora em vista do outro. Há um dialogismo que corresponde ao permanente diálogo, nem sempre harmonioso, existente entre os diferentes discursos que configuram uma comunidade, uma cultura, uma sociedade.

Todavia, um dos aspectos da interação verbal é o diálogo, concebido não apenas como comunicação em voz alta, de pessoas face a face, mas toda forma de comunicação e de todo tipo, constituindo uma fração da imensa corrente de comunicação verbal ininterrupta (relativa à vida cotidiana, ao mundo vivido, as representações contidas na linguagem).

Segundo Bakhtin (1999, p.33): "compreender um signo consiste em aproximar o signo apreendido de outros signos já conhecidos; em outros termos, a compreensão é uma resposta a um signo por meio de signos". E a dinâmica dos signos é contínua e única, colaborando para a existência de signos criados por um grupo organizado nas redes de suas relações sociais.

O método bakhtiniano tem como alicerce de base as relações com os outros. Valoriza a fala, o signo, a enunciação e afirma sua natureza social e não individual. Portanto, a interpretação dos signos que forma a imagem como um texto, não se constitui apenas uma representação individual, mas coletiva e que envolve processos dialógicos, rede de relações sociais e significados espaciais.

Para Bakhtin (1999, p. 36): "A realidade toda da palavra é absorvida por sua função de signo. A palavra não comporta nada que não esteja ligado a 
essa função, nada que não tenha sido gerado por ela. A palavra é o modo sensível de relação social". É importante destacar que este conhecimento espacial adquirido remete a presença constante de um interlocutor segundo Bakhtin (1999, p. 113):

\begin{abstract}
Toda palavra comporta duas faces. Ela é determinada tanto pelo fato de que procede de alguém como pelo fato de que se dirige para alguém. Ela constitui justamente o produto da interação do locutor $e$ do ouvinte. Toda palavra serve de expressão a um em relação ao outro. Através da palavra, defino-me em relação ao outro, isto é, em última análise, em relação à coletividade.
\end{abstract}

As relações estabelecidas ente o eu e o outro proporciona desvendar esse produto de interação entre os sujeitos, refletir sobre as significações diversas e que perpassa pelos discursos dos outros. O dialogismo colabora no estudo e compreensão da linguagem sígnica inerente às representações.

As interlocuções que ocorrem no espaço ribeirinho favorecem a construção de um imaginário, sendo que faz parte da convivência desse homem o imaginário, o sobrenatural, ambos marcantes na cultura amazônica. Os práticos, por sua vez, recorrem à dimensão simbólica para representar esse espaço por eles navegado e que se materializa através da linguagem, da construção de uma poética e dos processos interlocutivos.

De acordo com Bonnemaison (1981) este ele de ligação do homem e os lugares está carregada de afetividade e exprime essa relação cultural, simbólica no sentido amplo da palavra, ganhando uma significação na existência cotidiana desses profissionais.

Estudar o mundo vivido do homem permite visualizar a sua organização espacial, entendendo a subjetividade presente nesse vivido, considerando a cultura como geradora de sentidos e significados. E este conceito de mundo vivido é essencial para a análise do nosso trabalho.

Como afirma Tuan (1980), ao estudar as percepções e atitudes ambientais, o conceito de topofilia pressupõe o sentimento de afeição aos lugares, é o elo afetivo entre a pessoa e o lugar. O homem amazônico mantém de maneira viva e dinâmica essa afeição aos lugares, à paisagem, os sentidos operam nessa corrente de significação e colabora para o desvendar do espaço ribeirinho. 
Logo, os estudos das representações ajudam na compreensão do entendimento da categoria dos práticos pelo viés cultural, permeando pelas relações interlocutivas e dialógicas, na qual se externaliza a presença de um imaginário transfigurador e estetizante, bem como as narrativas míticas.

\section{O espaço do barco: da representação indo ao encontro da linguagem.}

O barco de acordo com Sousa (2004) não é apenas um meio de transporte com tipologias diferenciadas, usos ou funções tais como: escoamento da produção local (farinha, melancia, peixes, açaí, banana, entre outros), transporte de passageiros e cargas, e envio de mensagens escritas e orais através dos práticos e comandantes. Isto é, representa o lugar no qual se estabelecem as relações sociais e culturais; nele ocorrem diversos processos de interlocução, através do dialogismo defendido por Bakhtin (1999).

Neste sentido, a linguagem é muito importante para o entendimento desses processos interlocutivos, tendo em vista que é através dela que se percebe a construção ou produção de sentidos, dos signos sociais, a qual se dá no momento da fala, do encontro, da interação com o outro.

Isso constata que há uma convivência do homem amazônico com o barco, com o rio, marcada por uma representação simbólica, na qual começa pelo processo de construção das embarcações de madeira. Da mesma maneira, o processo da linguagem pelo qual vivenciam os práticos, nessa transmissão de saberes essenciais à navegação em se tratando do aspecto segurança, perpassa por este entendimento das estratégias e práticas de navegação utilizadas.

Para muitos ribeirinhos e barqueiros, o rio Madeira é tido como perigoso devido à quantidade de árvores, de pauzadas que descem o rio na época das cheias, das praias que se formam na época da vazante, dos temporais repentinos e dos moradores do rio: cobras grandes, jacarés, arraias, diversos peixes carnívoros e o candiru.

A noção de perigo, de medo, de estranhamento, uma vez registrada, parece contemplar umas das representações vividas no universo dos práticos, 
perfazendo o percurso dessa análise. De certa forma, o rio Madeira produz fascínio pela sua extensão, pela paisagem de seu entorno, dos animais que se encontram e qualidade de suas águas barrentas, revelando um ambiente ameaçador e encantador, quem sabe uma sensação de medo, em virtude do passageiro se deparar com o possível desconhecimento dos perigos iminentes e encontrados no ambiente amazônico.

Tuan (2005) ao estudar as paisagens do medo, evidenciou as várias espécies de medo que o homem enfrenta nas fases da vida, afirmando que 0 medo é subjetivo, é produto de um meio ambiente ameaçador. Por sua vez, ainda, Tuan (2005) ao trazer a temática das paisagens do medo, no qual ainda o define como sentimento complexo, destaca dois componentes: sinal de alarme e ansiedade.

O primeiro sinal de alarme relaciona-se a um evento inesperado e impeditivo no meio ambiente; e a resposta instintiva é enfrentar ou fugir. $\mathrm{Na}$ área ribeirinha, o prático, por exemplo, ao saber da vinda de um temporal não procura enfrentá-lo, mas desloca-se para a beira do rio e diminui a velocidade. Caso contrário, se insistir em permanecer no meio do rio poderá vivenciar um possível naufrágio devido à velocidade do vento, a força dos banzeiros, a estabilidade do barco poderá ficar ameaçada, sendo um risco para os passageiros e turistas.

Ademais, a resposta instintiva do prático é deslocar-se para a beira do rio, esperar o temporal passar um pouco, correspondendo a um procedimento de segurança.

O segundo componente descrito por Tuan (2005) atem-se à ansiedade, tida como sensação difusa de medo e pressupõe uma habilidade de antecipação. Voltemos ao prático, habilidoso na arte de pilotar com segurança os barcos, que procura ler os sinais escritos pelas nuvens, a imagem do céu nublado denuncia o que vem pela frente; assim, antecipa um procedimento de segurança ao fazer a leitura desses signos lingüísticos: nuvens escuras, céu nublado e banzeiro forte. 
Ao utilizar o seu conhecimento do rio, pressente os perigos iminentes, procura não se arriscar totalmente ao enfrentar um temporal que faz parte do meio ambiente real dos profissionais da navegação e dos turistas.

Contudo, esta ansiedade leva a procura por segurança, uma vez que na região amazônica ocorrem geralmente os naufrágios e por motivos variados desde as intempéries da natureza como a falta de manutenção adequada aos barcos de madeira.

Portanto, o trabalho dos práticos reveste - se de importância na vida da população amazônica, pois o barco é um dos únicos tipos de transporte disponíveis para os ribeirinhos, principalmente pelo preço da passagem. As comunidades ribeirinhas estão bem distribuídas ao longo de todo o rio Madeira e o prático é essencial na navegação praticada nesse rio.

Entender como se dá o trabalho desses profissionais no espaço ribeirinho significa compreender as estratégias de sobrevivência do grupo, o olhar que se constrói nesse espaço. Há um conjunto de símbolos e signos dos quais esses práticos fazem uso rotineiro desde a chamada de um tripulante com o pano banco ou a lanterna à noite, como um pedido de comunicação mediante mensagem falada ou escrita.

As narrativas contadas, podendo ser míticas ou não, representam o viver amazônico, pois evidenciam a interação com o meio ambiente, as quais simbolizam a convivência com o outro, com o grupo, com o desconhecido, evocando uma paisagem singular ao grupo e que passa de geração a geração. Não há limites entre o imaginário e a realidade, ambos confundem-se nessa interação, formando um conjunto cultural extremamente rico na Amazônia.

Sob tal perspectiva, o mito participa na construção do espaço dos práticos que elaboram um conjunto de explicações de seu "mundo", de seus valores, de sua organização. O espaço com todas as suas representações é a expressão viva do homem, torna-se um espaço humanizado, aliado ao projeto de sobrevivência do homem, é o seu lugar de liberdade, de trabalho, de encontros.

Pode-se compreender o mito segundo Eliade (1992) como uma realidade cultural complexa, pode ser abordada e interpretada de várias 
perspectivas. O mito entendido aqui corresponde a essa narrativa que ordena e mantém simbolicamente a estrutura natural e social do lugar ao relatar a história de um tempo primordial, na qual se evidencia as formas de navegar, as orientações de segurança e os desafios.

Mas o espaço de representações dos práticos se dá pela linguagem, pela presença das narrativas orais, na qual o mito colabora na construção desse espaço, desse lugar dos práticos. Assim, tanto o espaço quanto o lugar carregam consigo a marca da afetividade, das lembranças, o sagrado se manifesta de maneira expressiva. As narrativas são formas de conhecimento que os indivíduos adquirem das tradições e das relações ideais, realizadas no tempo de seus antepassados, e que se tornam a mediadora na relação com a natureza e também se constituem como uma estratégia de sobrevivência do grupo.

O espaço das representações dos práticos é marcado pelo universo das emoções, dos significados construídos coletivamente, dos medos, das paisagens e do estudo do rio, havendo um acúmulo de observação aliado à sensibilidade do prático.

Os mitos e as narrações míticas são elementos aos quais os indivíduos atribuem um significado e, que por sua vez, orienta-os no mundo. Para as populações ribeirinhas, as codificações estão distribuídas em dois universos distintos: o universo das águas e das matas, cada um contendo um conjunto de representações simbólicas.

\section{CONSIDERAÇÕES FINAIS}

\section{A Representação do Espaço dos práticos é mediada pela Linguagem}

A linguagem faz parte do mundo vivido das pessoas. Através dela se percebe a dimensão do imaginário, a construção dos signos sociais e de significados pertencentes ao grupo de práticos e ribeirinhos. De certa maneira, estamos imbricados nesse cenário de perceber, de viver, de sentir, de construir novas imagens e significados em cada momento. Viajando de barco, de um 
modo ou de outros, todos nós envolvemos pedaços da vida construindo experiências espaciais e culturais.

Há um espaço dos práticos mediado pela linguagem, pelas narrativas que compõem o imaginário da população ribeirinha e que estão presentes no modo de vida dos profissionais da navegação.

Por exemplo, a Cobra Grande se faz presente na vida dos moradores como uma guardiã de seus destinos, é visível para alguns, irreal para outros, porém, reverenciada com respeito pela maioria. No universo da navegação é temida, por ser um animal gigantesco e que pode naufragar a embarcação. Logo, os práticos a descrevem-na como sendo um animal grande, que costuma boiar, mora geralmente em lugares profundos e oferece perigo ao barco por haver essa possibilidade de colisão.

Há inúmeras narrativas que envolvem o mito da Cobra Grande na Amazônia e cada uma delas é recontada de uma maneira especial, prevalecendo aspectos singulares: é o gênio do mal, ora é do bem, tem o poder de paralisar os outros, aparece na forma de um navio iluminado, gosta de alagar e proteger as embarcações, há esse dualismo entre o bem e o mal na narrativa mítica.

Loureiro (1995) afirma o quanto à cultura amazônica é repleta de mitos e estetizações, logo se encontra mergulhada num ambiente onde predomina a transmissão oralizada e reflete de forma predominante a relação do homem com a natureza na qual se perdura um imaginário que privilegia o sentido estético dessa realidade cultural.

Sem dúvida, há nesse espaço do rio Madeira significados diversos, subjetividades marcantes e estetizações que fazem parte desse conjunto de representações encontradas no rio Madeira.

Nesse sentido, Bonnemaison (1981) menciona que o espaço social é produzido, vivenciado, concebido em termos de organização e de produção, havendo nessa interação uma significação e relação simbólica, gerando sentidos.

Sem dúvida, o lugar passa a ser apreendido, a partir da experiência que se tem dele, existindo um sentido de lugar no qual é dado pela experiência do 
corpo através das percepções dos sentidos. O lugar é dado a partir da experiência de cada um, se apresenta como vivenciado pelos habitantes, é constituído da experiência que se tem dele.

Contudo, a contribuição de bakhtiniana já vista mostra o dialogismo que se delineia nesse espaço de interação entre o eu e o tu ou entre o eu e o outro, trazendo de forma significativa à perspectiva de outra voz. Esse entrecruzamento de várias vozes evidencia as linguagens diversificadas, os signos construídos historicamente e os processos de significação.

Diante da diversidade cultural encontrada, vale mencionar que a geografia cultural tem colaborado em direção ao entendimento do modo de vida de populações da Amazônia, a exemplo dos práticos. Mas, sem dúvida é preciso continuar pesquisando mais a realidade geográfica desses profissionais e mesmo de outros segmentos de transporte na região.

De modo geral, entender a organização dos práticos significa compreender as relações sociais e culturais existentes, as estratégias utilizadas de navegação no rio Madeira e a forma de comunicação do grupo. $O$ estudo das representações torna-se uma oportunidade de compreender a presença do homem no meio geográfico, atendo-se às relações culturais, sociais e espaciais que se dão em determinados espaços, como é o caso de nossa área de pesquisa.

Em síntese, busca-se continuar trabalhando nessa interface da geografia cultural com os estudos baktinianos, constituindo um desafio epistemológico que vai tentando vencer a longo prazo. Mas, o primeiro vem sendo dado nessa construção e que começa sendo válido, no sentido de compreender cada vez mais o espaço dos signos sociais e das experiências dos sujeitos do rio Madeira, da Amazônia.

\section{REFERÊNCIAS}

BAKHTIN, Mikhail. Marxismo e filosofia da linguagem: Problemas fundamentais do método sociológico na ciência da linguagem. São Paulo: Hucitec, 1999. 
BARROS, D. L. Pessoa de; FIORIN, J. L (Orgs) Dialogismo, Polifonia, Intertextualidade: Em torno de Bakhtin. 2 ed. São Paulo: Editora da Universidade de São Paulo, 2003.

BONNEMAISON, Joel. Viagem em torno do território. In: CORREA, Roberto Lobato; ROSENDAHL, Zeny (Orgs). Geografia Cultural. Rio de Janeiro: EDUERJ, 1981.

CALLAI, H. C. Do ensinar Geografia ao produzir o pensamento geográfico. IN: REGO, N. et al. (orgs). Um pouco do mundo cabe nas mãos: geografizando em educação o local e o global. Porto Alegre: Editora da UFRGS, 2003.

CLAVAL, P. A cultura ribeirinha na Amazônia: perspectivas geográficas sobre o papel de suas festas e festejos. In: KOZEL, Salete et al. Expedição amazônica: desvendando espaços e representações dos festejos em comunidades amazônicas. "A festa do boi bumbá": um ato de fé. Curitiba: SK Ed., 2009.

ELIADE, Mircea. 0 sagrado e o profano. São Paulo: Martins Fontes, 1992.

FARACO, Carlos Alberto et al (Orgs). Diálogos com Bakhtin. 4 ed. Curitiba, Editora da UFPR, 2007.

KOZEL, S; COSTA SILVA, J; GIL FILHO, S.F. Da percepção e cognição à representação: reconstruções teóricas da geografia cultural e humanista. São Paulo: Terceira Margem; Curitiba:NEER, 2007.

KOZEL, Salete. As linguagens do cotidiano como representações do espaço: uma proposta metodológica possível. In: 12o ENCUENTRO DE GEÓGRAFOS DE AMÉRICA LATINA: CAMINANDO EM UMA AMÉRICA LATINA EN TRANSFORMACIÓN, 2009, Montevideo, Anais. Montevideo: Universidad de la República, 2009, CD-ROM. ISBN: 978-9974-8002-8-1.

LOUREIRO, João de Jesus Paes. Cultura Amazônica: uma poética do imaginário. Belém: Editora Cejup, 1995.

TUAN, Yi-Fu. Paisagens do Medo. Tradução de Lívia de Oliveira. São Paulo: Editora UNESP, 2005.

Topofilia: um estudo da percepção, atitudes e valores do meio ambiente. Tradução de Lívia de Oliveira. São Paulo: DIFEL, 1980.

SILVA, M.N. O espaço ribeirinho. São Paulo: Terceira Margem, 2001.

SILVA, Josué ett all (Orgs). Nos Banzeiros do rio: ação interdisciplinar em busca da sustentabilidade em comunidades ribeirinhas da Amazônia. Porto Velho: EDUFRO, 2002.

SOUSA, Lucileyde F. Navegar é preciso: barqueiros do rio Madeira, cultura, resistência e sustentabilidade. Dissertação de Mestrado, Universidade Federal de Rondônia, Porto Velho, 2004. 